\title{
Disentangling Individualism: Toward a Heuristic Tool for Cultural Analyses of Evaluations of Self and Society
}

\author{
Kobe De Keere ${ }^{1 *}$
}

1 University of Amsterdam, Nieuwe achtergracht 166, 1018 WV Amsterdam, NETHERLANDS

\section{*Corresponding Author: k.dekeere@uva.nl}

Citation: De Keere, K. (2018). Disentangling Individualism: Toward a Heuristic Tool for Cultural Analyses of Evaluations of Self and Society, Journal of Cultural Analysis and Social Change, 3(2), 12. https://doi.org/10.20897/jcasc/3993

Published: December 22, 2018

\begin{abstract}
Individualism belongs to the core of Western evaluative logic. This paper aims to determine what exactly now constitutes individualism as an often used cultural discourse and, more importantly, how its content varies depending on different semantic constellations. A systematic classification of different possible individualistic types of evaluation is proposed, which can eventually serve as a heuristic tool for further cultural analysis. The paper starts with identifying two essential meaning dimensions of freedom/control: (1) a self-dimension and (2) a society-dimension. Second, it explores how combinations of these different dimensions of meaning yield four different 'semantic fields', which all fall under the general heading of individualism, namely liberal, egalitarian, radical, and subjective individualism. These different types are described based on illustrations stemming from political, cultural, and philosophical domains.
\end{abstract}

Keywords: evaluation, discourse, self, individualism, cultural analysis

\section{INTRODUCTION}

People are evaluative beings: we do not only act upon the world, but simultaneously seek to interpret, classify, and vindicate these actions (Sayer, 2011). We feel obliged, out of concern for others and our surroundings, to understand, defend, and explain our choices and doings, and for this we rely on a multitude of beliefs and values. Repeatedly, it has been argued that, in modern Western societies, individualism increasingly came to constitute the core of our evaluative logic (e.g. Beck and Beck-Gernsheim, 2002; Dumont, 1977; Elias, 1991; Taylor, 1989). This is certainly not farfetched seeing that notions such as individuality or autonomy are ingrained in our juridical (i.e. principle of individual sovereignty), political (i.e. single vote democracies), and economic (i.e. capitalism as system of free consumption) system, and provide the cultural foundations for contemporary modes of social control (i.e. governmentality) (e.g. Rose, 1989; Foucault, 2008; Elchardus and De Keere, 2010). Consequently, it has become common practice to perceive the 'other' - in the same way as the 'self - as a singular individual capable of making autonomous choices.

That all members of society are seen as singular 'individuals' and that this view is a dominant cultural framework in Western contemporary societies, does not entail that we share the same understanding of what that individual is supposed to be, how it should act or how its relation with society is to be conceived. Highly valuing individuality is one thing, giving it content and having an opinion on how to put it into practice is yet another.

Although people often deploy the same individualistic notions to evaluate their lives and those of others, the way they use and interpret them can depend on their position in society, the historical timeframe they are a part of or the institutions they are connected to. As C. Wright Mills aptly stated: 
A symbol has a different meaning when interpreted by persons actualizing different cultures or strata within a culture. (...) A block in social actions, e.g. a class conflict, carries a reflex back into our communicative medium and hence into our thought (1963, pp. 435-6).

Hence, we might all be individualist, but do not necessarily endorse the same type of individualism, seeing that the latter necessary involves a multiplicity of meanings and views.

The objective of this paper is to now propose a heuristic yet systematic tool to analyse and categorize different individualistic notions people employ when evaluating their life and those of others. Whether these individualistic evaluations come about in the process of day-to-day interaction (e.g. during ordinary discussions) or manifest themselves within more complex cultural forms (e.g. novels or movies), we are still in need of an instrument to carefully and systematically read into these differences. Because if we place every type of individualistic evaluation under one large umbrella of individualism, then we do not take into account the importance of variations in ethical, cultural and political logics, which are crucial elements within both group boundary work (Lamont, 1992, 2000) as well as class conflicts (Sayer, 2011).

This paper begins by identifying the conceptual problems that mark the current sociological use of individualism by focussing on three popular topics in social science: neo-liberalism, class morality, and civic engagement. Second, I offer a short overview of past attempts to distinguish between different types of individualism. Finally, I propose a multidimensional reading of individualism by focussing on two major meaning dimensions of freedom and control, namely a self-dimension and a society-dimension. These two dimensions combined eventually render a categorization of four different types of individualism: liberal, egalitarian, subjective, and radical individualism. These are then described by giving examples stemming from different cultural domains, such as social movements, politics, ethics, and the arts. The latter step is not carried out with the intention of promoting more taxonomical analyses of ideas but to create a comprehensive heuristic instrument that will allow us to interpret and analyse individualistic evaluations in a more systematic and relational way.

\section{IDENTIFYING THE PROBLEM}

A lack of systematically taking into account variations in individualism results in three types of conceptual problems. First, individualism becomes a container term that qualifies as a label for any contemporary set of norms or values (e.g. neo-liberal ethos, longing for self-development, nonconformism, or the politics of emancipation). Second, if we refrain from systematically explicating the possible variations, social theory runs the risk of an ongoing proliferation of concepts that, in the end, might just refer to one and the same belief or set of values (e.g. self-actualization (Bell, 1976), self-realization (Honneth, 2004), self-expression (Inglehart and Welzel, 2005)). Third, a narrow and unidimensional definition of individualism easily leads to a reasoning whereby every cultural belief that does not fit that definition is deemed the opposite, namely collectivism (e.g. Triandis, 1995). Yet, seeing the strong individualization of social control in contemporary society (Foucault, 1990, 2008; Rose, 1989, 1999; Elchardus, 2009), it is rather unlikely that dismissing autonomy or individuality as a whole would be a very prevalent attitude within Western societies (although it is, theoretically, not completely unthinkable). As yet explained, it is more likely that there exist variations in how people value and use these concepts rather than fully reject them. Let me illustrate these problems by recalling how individualism as a concept is applied within the study of three popular topics of contemporary social science: neo-liberal ideology, class morality, and civic engagement.

\section{Neo-Liberalism and Individualism?}

Repeatedly, the argument is being made that neo-liberal policies and reforms are culturally justified through a discourse of individualism. People are accepting, as the logic goes, a loss of collective security and an individualization of social problems because they cling to their individualistic values too much. However, the manner in which these individualistic values are described differ drastically. It is, for example, often claimed that individualism fosters neo-liberalism because it implies models of selfhood that emphasize self-fulfilment and a search for self-realization (Cabanas, 2016; Honneth, 2004; Willig, 2009) or authenticity (Boltanski and Chiapello, 2005; Rose, 1989). In this way, individualism forces people on a quest for self-development, making them neglect the importance of collective support and regulation. Yet, many other writings on neo-liberalism employ individualism to denote a completely different set of values such as the love for competition, entrepreneurialism, and self-responsibility (Bröckling, 2015; McRobbie, 2015; Wacquant, 2009). In the latter case, neo-liberalism is not justified based on expressive values, but on a more classical liberal or utilitarian understanding of self and society that actually emphasizes restraint. Still, in both cases, these values are labelled as individualistic and often used indistinguishably.

The argument here is not that these analyses are mistaken and that a search for authenticity or, on the other hand, entrepreneurialism cannot be a defining feature of both individualism and neo-liberalism. But, what is 
problematic is that individualism is used as a vague container concept to denote every type of evaluation that appears to be related to neo-liberalism, although this seems to include very diverging sets of beliefs.

\section{Individualism as a Middle-Class Discourse?}

A second case wherein the use of individualism as a value concept is producing more confusion than clarity is the investigation of diverging class moralities. Repeatedly, it is argued that individualistic attitudes are typical for the (new) middle class. They seem, as research shows, to be characterised by an enthusiastic endorsement of selfdevelopment and strongly emphasize individual choice and expression (e.g. Lamont, 1992; Skeggs, 2009; Stephens, Markus and Phillips, 2014). Therefore, the conclusion is, to put it plainly, that the middle class are individualists while the working class are not.

However, this reasoning is problematic as it is a based on a very narrow understanding of individualism. It only focusses on individualistic attitudes such as expression and self-realization and, seeing that members of the working class do not uphold these particular beliefs, they are easily labelled as collectivists (e.g. Lamont, 2000; Mackenzie et al, 2006; Triandis, 1995). This necessarily implies that the working class are supposed to reject values such as autonomy or self-development. Yet, seeing the institutional (i.e. legal, political, and economic) constellation of the society that always presupposes at least some belief in singularity and autonomy, this is not all that convincing.

What is more likely is that members of the working class value a different kind of autonomy and selfdevelopment than their middle-class counterpart. As research, for example, revealed, the working class or those with downward social trajectories rely on notions such as perseverance, self-reliance, and hard work to frame their situation (Daenekindt, 2017; Kusserow, 2012) - values that remind us more of utilitarian individualism than of some type of collectivism. In this context, Kusserow (2012) even argues that working-class morality is actually characterized by, what she calls, a hard type of individualism. Moreover, plenty of research also demonstrated that members of the working class actually often support anti-collectivist values as they appear more distrusting of institutions (Elchardus and De Keere, 2013), often oppose political egalitarianism (De Keere, 2018; Houtman et al., 2008), and show a stronger support for nonconformism and independence (Hochschild, 2016; Willis, 1977). Hence, it would be more fruitful to allow for a varied understanding of individualism that does not only capture middle-class value patterns, but also grasps working-class evaluation without having to falsely label them as collectivist.

\section{Civic Individualism?}

A third case in which the concept of individualism is crucial yet used in an unspecified way is the study of civic engagement. Ever since the writings of Tocqueville - one of the first to use the term individualism - on early American civil society, it is claimed that individualistic attitudes inevitably engender a disintegration of public life (see also Lasch, 1991; Putnam, 2001; Sennett, 2003). Rampant individualism, as the argument goes, creates isolation and pushes for a commodification of social life, leading to the pursuit of self-interest as the only motive to engage in the public sphere.

Empirical research on volunteering, however, depicts a very different role for individualism. Apparently, people rely strongly on individualistic notions to justify and motivate their active participation in society. As Wuthnow showed, values such as the pursuit of happiness and self-realization seem to be crucial in understanding people's motivation to volunteer (1995). Instead of collectivism or authority, people turn to their self-expression (Welzel, 2010) or self-fulfillment (Kelemen et al., 2017) to frame their civic engagement. Hence, the type of individualism (i.e. valuation of self-interest and egocentrism) that Putnam and others have in mind might indeed erode civil engagement, yet there seems to be another, more civic (Seidman and Meeks, 2010), responsible (Wilkinson, 2010), or moral (Markse, 1987) type of individualism that actually fosters social participation. Hence, the question is not whether individualism has the performative force to hollow out the public sphere or not, but which type of individualism could be responsible for this and which type could have to opposite effect. This, again, asks for a systematic classification of different types of individualism.

Of course, these are only three examples but the way individualism is used in these cases is certainly not idiosyncratic. To be able to deal with these different conceptual problems, without dismissing the use of individualism all together, we need to construct a systematic framework that allows us to not only read and label these individualistic values more consistently, but also bring them into relationship with each other. Hence, the goal is to develop an analytical instrument that not just names variations in individualistic beliefs but also articulates how they configure together. How do they relate to each other in terms of similarities and differences and what are their basic premises? Before we come to such a heuristic tool, it is necessary to first review some of the main distinctions in individualism that have already been made within social science. 


\section{VARIATIONS ON A THEME}

From the birth of the sociological discipline, scholars have tried to bring some clarity into the semantic fog created by the undefined use of individualism by discriminating between different types of individualism. The most famous, and probably oldest within sociology, is the distinction made by Durkheim between a utilitarian and a bumanistic individualism (Durkheim, 1973). According to Durkheim, critics of individualism often conflate individualism with egoism, an interpretation that would only fit the utilitarian individualism of the Physiocrats or Herbert Spencer. The kind of individualism he himself defended starts from a humanist tradition and is characterized by a sacralisation of the individual in the abstract. Another founding father of sociology who saw a dichotomy within individualism was Simmel, who distinguished quantitative from qualitative individualism (Simmel, 1950). The former type has its roots in $18^{\text {th }}$ century France and comprehends the individual essentially as a singular yet indistinguishable part of humanity (Einzelheit). Qualitative individualism, on the other hand, took shape in Germany during the $19^{\text {th }}$ century and focusses on the uniqueness of every individual (Einzigkeit), placing high value on originality and self-realization.

Outside of sociology, classical distinctions in types of individualism have also been made. John Dewey, for example, wrote a pamphlet titled Individualism Old and New (Dewey, 1999) wherein he argues against what he calls old individualism, characterized by a culture of self-interest, materialistic concerns, and mechanistic social interaction. According to him, this individualism was rampant in the U.S. after the First World War and strengthened the corporate nature of society, while weakening social cohesion. For this reason, intellectuals needed to develop a new individualism, allowing people to react against the corporateness of society and rendering free and meaningful interaction possible again.

On the other side of the ideological spectrum, we find Friedrich von Hayek's distinction between true and false individualism (Hayek, 1948). In the same way as Dewey, he comprehends individualism as a set of principles, offering people guidance in solving both public and private problems, but warns his readers to be cautious of the type of individualism they endorse. The kind of individualism Hayek opposes is typified by a confidence in a rationalistic organization of society. This 'social contract individualism', as Hayek also calls it, 'always tends to develop into the opposite of individualism, namely, socialism or collectivism' (1948, p. 4). By contrast, true individualism starts off from the liberal tradition and is 'anti-rationalistic'. Instead of social engineering, society should depend on free collaboration and the permanent acknowledgement of a personal sphere of responsibilities.

This tradition to (re-)interpret, subdivide, or discover new forms of individualism had not come to a halt by the middle of the $20^{\text {th }}$ century. Since the 1970s, sociology witnessed a revival of the Tocquevillian use of the concept of individualism as both a cause and a consequence of rising social isolation and the privatization of public life (e.g. Putnam, 2001; Sennett, 2003). They argue that contemporary society is typified by a disintegration that manifests itself in public nihilism, political apathy, and societal indifference. The most radical formulation of this way of thinking can be found in the work of Lasch (1991), who contends that narcissistic individualism has become a quintessential feature of contemporary society.

Yet, at the close of the $20^{\text {th }}$ century, some sociologists started to endorse a more optimistic reading of the notion of individualism. The popular individualization thesis (Beck and Beck-Gernsheim, 2002), for example, entailed the idea that increasing economic prosperity and social emancipation eventually also engendered, besides structural changes, a reflexive individualism, culturally typified by an emphasis on tolerance, relativism, and a longing for selfrealization. This reflexive individualism shows much resemblance to what Bellah and colleagues (Bellah et al., 1985) call expressive individualism, which they then distinguish from utilitarian individualism. The latter entails an individualism based on puritan values such as self-interest, discipline, and personal responsibility. Expressive individualism, on the other hand, involves a subjective ethic of self-expression, urging people to find their true selves (see also Inglehart and Welzel, 2005).

What this short (and incomplete) inventory demonstrates is that individualism is a concept that is used to denote a wide range of notions (e.g. humanity, autonomy, authenticity, responsibility, and reflexivity) and therefore strongly varies in content depending on the emphases that are placed. Yet, for a systematic and contemporary analysis, these subdivisions of individualism fall short in two key ways. First, many distinctions (e.g. those of Durkheim, Simmel or Dewey) are in need of a cultural update so they are also applicable to more 'recent' societal developments. Secondly, and more importantly, most existing conceptual subdivisions in individualism do not really explain how the different variation actually relate to one another: what exactly are the differences and commonalities? This makes it very difficult to really apply the above divisions as a research instrument. Therefore, we are in need of a more systematic and gradual classification that explicates the relationships between all these sets of values so that it, eventually, can serve as a tool for cultural analysis. 


\section{SELF AND SOCIETY}

In order to devise such a classification, we first need to disentangle the skein of concepts that constitute individualism by focussing on two fundamental dimensions of meaning making, i.e. a self-dimension and a societydimension. Since individualism - in its most literal meaning - can be understood as the 'ism' or ideology of the individual, it is evident that the self, or allied terms such as individual, ego, or persona, qualifies as a core notion. Yet, when the term individualism is used, it generally involves much more than merely a view of the self - it includes an understanding of its relationship with society. As Alexander (1982, pp. 64-126) stated, every social theory, and, by extension, social discourse, needs to answer to an actor- and order-question, i.e. 'How do we understand the actor?' and 'How do we conceive social order?'

However, as the above account demonstrates, many different individualistic answers are possible to this doublesided question. In order to systematize the different possible answers, I propose here to focus on the importance of freedom and its counterpart, control. First, because freedom is a concept that lies at the heart of both individualism (Lukes, 1973; Dumont, 1977) as well as contemporary forms of social control (Foucault, 1990; Rose, 1999; Elchardus, 2009). Second, we recover two well-known conceptual antagonisms within Western cultural history in this way. The first antagonism relates to the actor-question and is about to what extent the actor should control or, on the contrary, liberate their own self. This division between self-control and self-liberation corresponds closely to the long-standing Western tradition that sees a tension between reason and will, control and expression, or restraint and passion. Second, to answer the order-question, we can turn to Isaiah Berlin's distinction between positive and negative freedom (1969). Whereas the latter concept understands autonomy as rejection of control, the former view entails a belief in autonomy through societal regulation. By combining these two dimensions of meaning, we come to a classification of four semantic fields that hold the building blocks for different individualistic discourses.

Furthermore, it is also important to consider that beliefs and discourses can vary in two ways: (1) on the basis of the concepts they employ and (2) by the manner in which the same concepts are being related to each other (Freeden, 1996). The different types of individualism are above all a consequence of the second sort of variation. Concepts, as Freeden makes clear, have an indeterminate rather than intrinsic meaning and are therefore susceptible to morphology $(1996,62)$. They are the product of human activity and consequently acquire meaning through both synchronic (i.e. semantic relationships between concepts at a given point in time) and diachronic (i.e. strings of historical groundings that determine variations in contents) processes (1996, 51-2). Hence, this classification is not about the rejection of any understanding of individuality, but about gradual differences in the emphases people put on certain interpretations and notions.

The classification proposed here, by reducing a set of complex and diffuse cultural evaluations to only two dimensions of meaning, is ultimately heuristic and it is therefore important to bear in mind that it is always gradual and inevitably characterized by overlap. As such, it is imperative to emphasize that this classification would lose its purpose if applied as an end in itself (i.e. classifying discourses as separate entities into a taxonomy) instead of as a means for cultural analysis (i.e. systematically interpreting how individualistic values relate to each other).

I continue with describing how evaluations of self and society can morph depending on a specific emphasis on either freedom or control.

\section{Self-Dimension}

The history of Western thought is not only characterized by an increasing cultural prominence of the self, but has also yielded different interpretations of what this self actually entails (Mauss, 1938; Taylor, 1989). In this regard, any self-conception needs to be capable of answering three sub-questions: an ontological, an epistemological, and an ethical question or, respectively, 'What is the self?', 'How can it be known?', and 'How must it act?' Depending on whether either freedom or control is valued, these questions can be answered in drastically different ways. Or, to be more precise, it can be read from a self-control or self-expression perspective.

From a self-control perspective, the ontological question can be answered by stating that the individual is primarily a project, always prone to improvement and is never a 'given' but must be controlled. Such a belief has its roots in the Protestant and Puritan idea that God's grace can only be earned if one exhibits determination and willingness toward self-improvement (Taylor, 1989, pp. 211-233). A reasoning that was further developed during the Renaissance (Burckhardt, 1914) and later secularized by the rationalistic philosophers of the Enlightenment (Taylor, 1989).

This relates to the epistemological question, namely that the true self can only be known through reason. The self must be detached from its particularistic desires and needs to be able to reform itself in accordance with the laws of reason. Therefore, the essence of the self never lies in its specific attributes or traits, but in how closely the individual corresponds to an ideal or rational self. The human self thus only appears when it constrains its irrational passions and inclination, which always impede balanced thoughts and behaviour. This ideal of self-objectification 
often leads to a morality that emphasizes self-control and the ethical question is therefore answered in terms of discipline, restraint, and willpower.

The self-expression perspective is opposite to its self-control counterpart. Ontologically, the self is, according to this perspective, not made through control but interpreted as something that has to be liberated. The assumption here is that every individual has an unchangeable and unique core, which determines the essence of their being. Therefore, a person's authentic particularities need to be safeguarded as they define the essence of the individual. This view finds its philosophical roots in the writings of Rousseau and Montesquieu, and was further developed by German Romantics (Ferrara, 1998; Taylor, 1989).

From a self-expression point of view, answering the epistemological question has nothing to do with detachment or self-objectification. Rather than disengagement, the essentialist self asks for a full-on exploration and liberation of the self. Here, self-knowledge thus primarily entails discovery and disclosing, since the true individual lies buried under many layers of education, habituation, and socialization. This view yields, on the one hand, a strong positive valuation of notions such as authenticity, uniqueness, and intuition, and, on the other, a rejection of control, conformism, and restraint.

This same logic also steers us toward answering the ethical question in terms of authenticity and self-expression. An act is deemed good not because it corresponds to some external moral standard, but because it starts from a genuine 'urge' to do good. According to this view all moral deeds start off from a worthy moral individual, depending, in turn, on how authentic one is toward the deed, i.e. it is the intention - which has to be genuine and truthful - that determines the value of an act and not its actual result (Ferrara, 1998).

\section{Society-Dimension}

To answer the order-part of the question, we need to look at different interpretations of how to conceive individual control within society. In order to obtain a more systematic view of this issue, Isaiah Berlin's famous division between two types of freedom (Berlin, 1969) is - although certainly not unproblematic ${ }^{1}$ - very instructive. In his seminal paper 'Two concepts of liberty' (1969), Berlin argues that there are two possible and even rival interpretations of the question 'What is freedom?', namely a positive and a negative approach. Negative freedom pertains to the question 'What is the area within which the subject - a person or group of persons — is or should be left to do or be what he is able to do or be, without interference by other persons?' $(1969,121)$ Hence, it implies that the individual is free only to the extent that one is liberated from constraints, intrusion, or obstacles. This type of liberty is termed negative, as freedom itself is not given any content but is completely defined by the absence of something.

In contrast to a negative interpretation, positive liberty is about the freedom to do something, or, more specifically, about the possibility to realize or develop oneself. However, people can only develop if the necessary conditions are fulfilled, i.e. if they have the required resources and capabilities. This view carries two important implications. First, that liberty is given some content: if the possibility of self-development is the essence of liberty, it implies a certain definition of what self-development entails. Second, it suggests that a particular degree of control is allowed, as long as it leads to individual development. Therefore, positive freedom, as Berlin wrote, refers to the question: 'What, or who, is the source of control or interference that can determine someone to do, or be, this rather than that?' $(1969,122)$.

\section{FOUR TYPES OF INDIVIDUALISM}

Now that the two meaning dimensions of individualism are defined, these can be combined in order to arrive at four separate semantic fields, each consisting of a different collection of individualistic notions and values. In the next four sections, I describe these specific combinations or styles of individualism, namely liberal, egalitarian, subjective, and radical individualism (Figure 1).

\section{Liberal Individualism}

When we combine a self-control perspective with a negative view on liberty, we end up with a traditional liberal variant of individualism. The fathers of liberalism (e.g. John Stuart Mill and Adam Smith) all plead for a minimization of public interference in the lives of civilians. They argue that there are certain domains in life, specifically in the private sphere, where the liberty of the individual should almost never be curtailed. From this viewpoint, self-interest is in itself not seen as a threat to societal stability. On the contrary, the pursuit of personal

\footnotetext{
${ }^{1}$ Berlin forbears, for example, to take into account important factors such as the content of individual desires (Christmas, 1991) or the general conditions under which non-interferences is guaranteed (Pettit, 2001).
} 


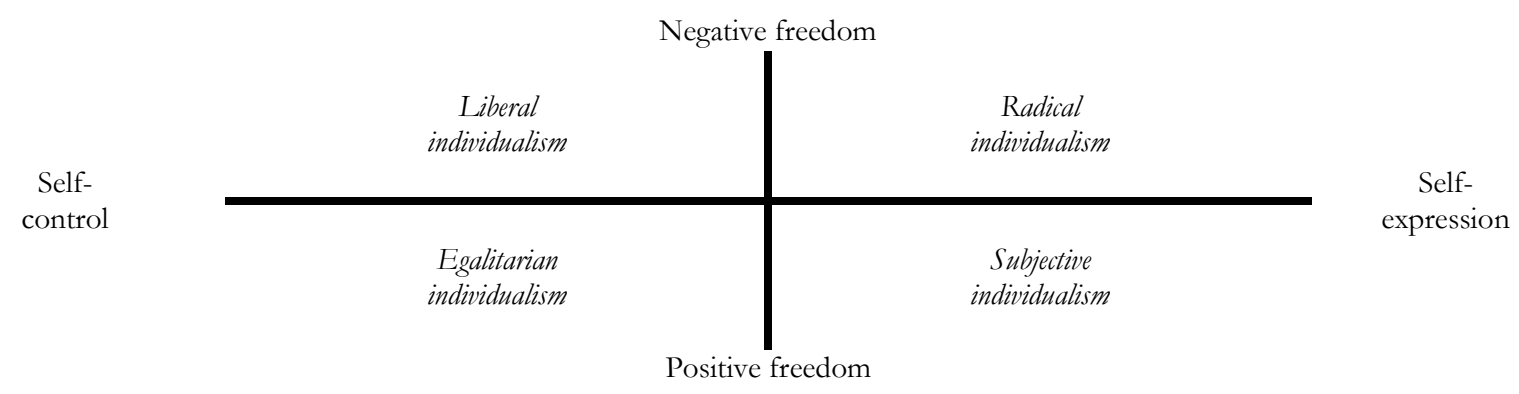

Figure 1. Two meaning dimensions and four types of individualism

gain can even be viewed, often by referring to Smith's notion of the 'invisible hand', as a mechanism that will eventually engender greater general welfare.

However, liberal discourses are not only characterized by a defence of negative liberty, but also entail a selfcontrol perspective. According to Taylor, much of liberalism is based on the Lockean idea of a punctual self or 'the possibility to remake ourselves in a more rational and advantageous fashion' $(1989,170)$. Thus, from a liberal perspective, the idea that individuals should be free from interference needs to be accompanied by a belief that people are capable of a certain self-rationalization. In this regard, the liberal ideal of self is a restraining, calculating, and pro-active individual who takes responsibility for their situation and acts in order to better it, i.e. an economical or entrepreneurial self (Holmes, 1997).

Outside of its philosophical tradition, this type of individualism became an important socio-political discourse among the wider sections of society during the second half of the $19^{\text {th }}$ century, and most notably within AngloSaxon countries. One of the most influential English political and social theorists of that period was without doubt Herbert Spencer. He became famous for what was later called 'social Darwinism', which is a relatively radical form of liberalism, explicitly combining a belief in self-control with a defence of negative freedom:

What now is the most important attribute of man as a moral being? (...) May we not answer the faculty of self-control? This it is which forms a chief distinction between the human being and the brute (Spencer, 1851, p. 185).

If government was to interfere, as Spencer's 'survival of the fittest' logic further goes, it would disrupt the natural order of things and those who were capable of restraint and self-control would not be rewarded, whereas the 'brutes' would survive. That is why the state should not try to install an artificial form of equality by supporting those who lack the discipline to seize their opportunities.

From a cultural viewpoint, one of the most important exponents of this liberal individualism is perhaps the notion of the self-made man (Howe, 1997), embodied by a successful figure, ranging from Benjamin Franklin to Steve Jobs. Benjamin Franklin's influence - in addition, of course, to being one of the founding fathers of the U.S.A. - actually stems from writing one of the oldest and most popular self-help guides, namely 'Poor Richard's Almanack' (1732-1758). In this annual publication, he promoted the idea of general self-improvement through the cultivation of liberal virtues, such as temperance, order, resolution, frugality, and moderation. Within the literary field, liberal individualism finds its most explicit advocate in the person of Ayn Rand. In her best-selling science fiction novel 'Atlas Shrugged', for instance, Rand tells the story of a society in which most creative minds and entrepreneurs are on strike as a protest against the over-regulative government.

Reflecting on the classical and contemporary interpretation of individualism, as described above, we can say that liberal individualism actually corresponds best to what both Durkheim and Bellah termed utilitarian, and Hayek, in his attempt to defend it, true individualism. Further, Dewey's critique on the American, capitalist, and corporatist individualism is actually directed primarily toward a liberal interpretation of self and society.

\section{Egalitarian Individualism}

Egalitarian individualism is a discourse that results from combining a belief in positive freedom with a selfcontrol perspective. In this case, freedom is not interpreted as liberation from something, but as offering the possibility to develop oneself through collective support. All members of society thus need to attain the same level of development. Here, self-development is defined as the construction of an ideal citizen and equal member of the group. It is exactly this type of individualism that Simmel termed quantitative, and was defended by Durkheim while being fiercely contested by Hayek.

Because egalitarianism is mostly associated with only favouring collective solutions to problems, the political examples, such as syndicalism, socialism, or communism, are often understood as holistic or hierarchic rather than individualistic (e.g. Triandis., 1995). Yet, as both Berlin (1969) and Dumont (1977) argue, these - although 
sometimes totalitarian - ideologies have their roots much more ingrained in individualism than in the holistic tradition.

In order to accommodate both freedom and equality, proponents of egalitarian individualism have often employed - implicitly or explicitly - notions such as bomo politicus, 'universal man', or a 'general will'. Inequality, from this viewpoint, is merely a result of particularistic and fabricated circumstances that have disrupted the natural order, which is one of harmony and equality. This idea is grounded in a firm belief in bottom-up solutions to societal problems and restabilising the social contract. Hence, egalitarian individualism often manifests itself in an atavistic nostalgia for a lost organic collective.

The assumption that something of a 'general will' exists in every individual also has implications with regard to how the self is interpreted. The individual should above all strive toward being integrated within the collective. The construction of such an ideal individual involves the cultivation of self-control, from which, eventually, the individual as well as the group, nation, or volk can benefit. Take Fichte's writings on the creation of a new German nation through a re-education of all German citizens for example (Fichte, 1922). To arrive at such an ideal citizenship, he said, the cultivation of self-mastery is essential, because 'the root of all morality is self-possession, self-control, the subordination of the selfish instincts to the idea of the community' (1922, 175). A same logic can be discovered in the normative work of Durkheim. In his 'L'éducation moral' (Durkheim, 1934), he proposes three elements that can serve as foundations for a morality adapted to modern secularized life, namely (1) attachment to others, (2) autonomy or self-determination, and (3) discipline or self-mastery, notions that all lie at the heart of egalitarian individualism.

Finally, egalitarian individualism has also left its mark on the literary domain. Two influential and much-read authors who spring directly to mind are Charles Dickens and Émile Zola. Several of their stories are about denouncing the Spencerian idea of 'deserving poor' and revealing the social disruption and poverty resulting from early industrialization. With that, it is clear that many of Dickens' or Zola's heroes excel in Victorian values such as willpower and moderation, whereas the antagonists are often characterized by their greed, decadent lifestyles, or drunkenness.

\section{Subjective Individualism}

This individualism is termed 'subjective', as the combination of a positive understanding of freedom - which entails a belief in collectively supported self-development - with an emphasis on self-expression, leads to answering the actor- and order-question in a very subjectivist and person-centred manner. In contrast to egalitarian individualism, the level of self-development is not assessed by measuring how well an individual is incorporated into the group, but by evaluating how capable people are at expressing their 'own selves'.

Seeing the positive understanding of freedom, which allows for some degree of control, self-expression is only possible through collective support. In other words, the individual can only become a self under the guidance of specific institutions. Consequently, an emphasis is placed on personal, pedagogical, and therapeutic support. Hence, because of its positive evaluation of societal interference, this individualistic style is characterized by a belief in institutional solutions, organized welfare, and psychological guidance.

This belief in the collective importance of self-realization characterizes, for example, the humanistic psychology developed during the mid-20 th century by psychologists such as Carl Rogers (1961). Humanistic psychology is mainly based on Maslow's principle that, when basic needs are fulfilled, we all develop a natural tendency toward self-actualization, manifesting itself in higher levels of creativity, spontaneity, tolerance, and problem-solving capacities. The crux of this therapy is that the psychologist must always find and encourage the patient's potential toward authentic inner development. This belief in a universal tendency toward self-actualization also resonates within the capability approach as developed by Sen and Nussbaum (Nussbaum, 1988), an approach that has, for example, been highly influential within policy-making institutions such as the United Nations (e.g. the philosophy behind the Human Development Index). It is clear that the United Nations supports a positive understanding of freedom whereby self-development is institutionally embedded.

In addition to therapy and policy, subjective individualism also left its mark on the political debates of the second half of the $20^{\text {th }}$ century, in particular through the rise of new leftist, emancipatory, and ecological movements, which mainly involve quality of life and identity politics. Many of these movements were, as C. Wright Mills pointed out (Mills, 1960), characterized by a rejection of traditional socialist ideologies that envisage an utopian endpoint for humankind. These 'grand narratives' are perceived by new leftists as objectifying cages that force people into political straightjackets that deny them an authentic and personal engagement within society.

In general, this subjective individualism is widely diffused within popular culture through the rise of therapeutic self-help books, magazines, and television shows (De Keere, 2014; Illouz, 2008). But, contemporary writers such as Milan Kundera and Jonathan Franzen also articulate this longing for authenticity or therapeutic self-actualization and the problems it engenders. In movies, these themes have become popular since the mid- $20^{\text {th }}$ century as well, be it in the existential dramas of Ingmar Bergman or the psychological comedies of Woody Allen. 
After having described this subjective individualism, we see that, in many ways, it corresponds to what Bellah and colleagues called expressive individualism (1985). It is a psychological yet institutionalized view on self and society, engendering a certain existential insecurity and longing for authenticity. This is a style of thinking that has regularly been defined as mainly characteristic of affluent Western societies (Elchardus and De Keere, 2010; Inglehart and Welzel, 2005).

\section{Radical Individualism}

Finally, the last type of individualism that needs to be described is called 'radical', because it rejects any form of control, not only stemming from others but from the self as well. Similar to subjective individualism, radical individualism implies an expressive interpretation of the self, but combines it with a negative understanding of freedom, declining any form of social interference. The self is understood as inevitable ('I am who I am') and control or regulation of it therefore needs to be denounced at all times, as it can only result in hypocrisy and deceit. This self-conception also manifests itself in a positive valuation of notions such as genuineness, uniqueness, and nonconformism. However, this does not have much to do with an institutional supported project of selfactualization and emotional wellbeing, but more with a hedonistic cultivation of gut feeling and impulse.

Academically speaking, this perspective has hardly been canonized within philosophy. The most important exceptions are perhaps Stirner (1907) and Tucker (1926). Both are considered to be founding fathers of radical anarchism. Their thinking is characterized by a rejection of authority, moral rights, and social regulations while advocating independence, hedonism, and unconditional self-expression. Stirner is in particular sceptical about individuals who uphold externally defined goals; the only thing people can rely on and believe in is their own true self:

Why, I myself am my concern, and I am neither good nor bad. Neither has meaning for me. The divine is God's concern; the human, man's. My concern is neither the divine nor the human, not the true, good, just, free, etc., but solely what is mine, and it is not a general one, but is - unique, as I am unique (1907, 6).

The consequence of this line of thinking is an acceptance of egoism as a natural feature of humankind.

Politics that want to tap into radical individualism do not start from traditional ideologies such as liberalism or egalitarianism, but primarily imply an anti-establishment, anti-political, and anti-institutional position. According to this radical point of view, we are ultimately on our own and there are no clear social rules we can follow. In the end, governmental representatives or politicians also just follow their own feelings and interests and an altruistic engagement in the public sphere is therefore doomed to fail.

Although hardly influential within the philosophical or political field, radical individualism has always had many representatives within the artistic domain. This is echoed in the romantic ideal of the bohemian artist who renounces any societal and cultural mores and only follows their own instincts. The most outspoken example of this is probably the 'art of transgression', which aims at violating and even outraging social convention, while cultivating animal instincts and the abnormal (e.g. George Bataille or Antoine Artaud). Within popular culture, radical individualism also had clear influence. Not only via the screening of dystopian movies, including 'Clockwork Orange' or 'Fight Club', that involve a glorification of violence and sexual excess, but even more so through the popularity of late- $20^{\text {th }}$ century subcultures such as punk or gangsta rap. Musicians of these genres are often characterized by the importance they give to a nonconformist and 'just be yourself' attitude, which is combined with an anti-establishment mindset (Lewin and Williams, 2009).

Referring to the more classical interpretations of individualism, we can now grasp that it was actually this radical individualism that was feared by the likes of Tocqueville (Lukes, 1973). But, also more contemporary scholars implicitly or explicitly - warned against the rise of a type of individualism that would potentially stimulate a hedonistic and egocentric culture (Lasch 1991; Bell, 1976).

\section{APPLYING THE SCHEMA: AN EXERCISE}

Coming back to the three cases that were used to illustrate the problem, i.e. neoliberalism, class morality, and volunteering, we can now apply the heuristic classification to better interpret the arguments and empirical findings.

In the case of neo-liberalism, it is not just individualism in general that seems to serve as a justificatory framework for socioeconomic reforms. It seems that both liberal individualism, with its emphasis on self-regulation and entrepreneurialism, and subjective individualism, highlighting the importance of emotional self-realization, play a crucial role in sustaining neo-liberalism. Yet, how these two types are used in varying settings and by people with different social positions is now up for investigation. Moreover, to fully understand the relationship between individualism and neo-liberalism, we should also explore how egalitarian and radical individualism might possibly serve as evaluative frameworks that allow for cultural critiques on neo-liberalism. 
Also with respect to class morality, the classification helps us to reinterpret the different evaluative positiontakings that typify the different class fractions. On the one hand, it seems that the individualistic attitudes popular among the (new) middle class, i.e. emotional self-fulfilment and expression, primarily fall within the semantic field of subjective individualism (e.g. Kusserow, 2012; Lamont, 1992; Skeggs, 2004; Stephens et al., 2014)

On the other hand, it seems that some of the collectivist tendencies of the working class, i.e. focus on interdependence and community life (e.g. Lamont, 2002; Stephens et al., 2014) does not necessarily makes them traditional collectivists but rather egalitarian individualists. However, as previous research demonstrated, the dominated fractions of society seem to be characterized by a mixture of (sometimes contradictory) value patterns (Houtman et al., 2008). With their emphasis on self-reliance and thrift, a part of the working class seem to actually adhere to a more liberal instead of egalitarian type of individualism, while yet another fraction appears to be more drawn toward radical individualism (i.e. anti-institutional and nonconformist attitudes). The classification proposed here now offers a unifying framework to explore how these attitudes actually relate to each other. This allows us, in the future, to explore how different positions and trajectories within the working class itself eventually engender varying understandings of both self and society.

Finally, this classification also serves as a tool to better understand the performative role of individualistic attitudes within the study of public engagement. As yet explained, the type of individualistic values that, according to Tocqueville, and later scholars such as Sennett and Putnam, has the potential to erode public engagement would be primarily related to radical individualism as it entails a refusal of conformism and rejection of societal participation. On the other hand, the more civic individualism that seems to have a strong positive influence on the desire to participate within the public sphere (Markse, 1987; Seidman and Meeks, 2010; Wilkison, 2010) corresponds with egalitarian individualism as described above. Moreover, here we can expect as well that not just one set of individual values can be influential. Depending on people's social positions, different types of individualism can be employed to justify their different civic roles. For example, the relation between a belief in self-expression and civic engagement (Welzel, 2010; Keleman et al., 2017), might be primarily stemming from middle-class participants, who already have a stronger tendency towards subjective individualism (Kusserow, 2012; Lamont, 1992; Skeggs, 2009) and will thus rely on this set of values to justify their participation.

\section{CONCLUSION}

The objective of this paper was to construct a heuristic instrument that would allow us to read into different sets of individualistic beliefs. The goal was not, however, to just name different type of individualism, but, to above all, explain how they relate to each other in a systematic way. In order to do so a schema based on two basic meaning dimensions, i.e. a self- and society-dimension, was suggested. These dimensions do not only allow for a categorization into four types, but also aid in thinking relationally about the differences. As Freeden (1996) explains, variations in ideas do not only happen because different concepts are employed but also due to the configurations in which they are being placed. Differences between ideas and values are therefore not necessarily categorical but more often gradual.

For these reasons the proposed schema, based on gradual meaning dimensions, can help to improve cultural analyses that aim at a systematic comparison of individualism between groups and over time. In doing so, it can aid in further solving the three conceptual problems, as identified at the beginning: (1) individualism as a container term, (2) continuous proliferation of new concepts for the same type of individualistic values, and (3) avoiding false dichotomies between individualism and collectivism.

Clearly, the intention is not to present this categorization as a framework that would allow us to comprehend all possible cultural expressions within society. Evidently, religion, gender, nationality, tradition, or ethnicity are other important factors that determine and give content to the types of evaluations that circulate within society. However, the scope of this classification might be quite large seeing that contemporary control mechanisms rely heavily on a commonly shared belief in a singular and autonomous self (i.e. individuation), and people are therefore almost obliged to uphold a certain interpretation of the individual and its autonomy. In other words, there is such a strong consensus on individualism in modern societies that it is difficult to imagine that one does not value its core notions.

Yet, the dialectic between (1) the consensus on individualism and (2) the different possible interpretations, stimulates a cultural dynamic that characterizes much of inter-group competition and coalition formation. On the one hand, the consensus on the worth of autonomy and individuality - at least in its most abstract form - has the potential for concealing conflicts as well as rendering alliances between groups possible. In other words, ideologically conflicting groups can always justify their collaboration by emphasizing their shared belief in selfdevelopment and personal liberty and so widen their influence on society. On the other hand, when surpassing this consensus, the different interpretations of individualism can equally be employed as instruments in a struggle over group interest and identity. 
Hence, basically all members of modern society will march under the banner of individuality. Yet, different positions, groups, or parties will appear once people start to specify, on the two basic meaning dimensions, what they mean when using these notions. Therefore, individualism has the ability to both unite (through vague consensus) and divide (through expressing specific interpretations) different social groups. The classification proposed here can prove to be a crucial tool to eventually disentangle this cultural dynamic, inherent to individualism as a powerful cultural discourse.

However, making a gradual distinction between four different types of individualism, could not only be instrumental in respect to synchronic comparisons between groups, but it can also yield clear benefits in relation to a diachronic study of cultural transformations. As Savage (2009) argued, social scientists have a tendency towards epochalism, often claiming we now live in a new social order that is drastically different from previous modes of social and cultural organization. From reflexive modernism (Giddens, 1992) to post-modernism (Beck and BeckGernsheim, 2002), the cultural revolutions seems to relentlessly succeed one another. However, these social changes are maybe not as categorically as they are often depicted, at least not in terms of value patterns, but might more often be cyclic, relational and gradual (Savage, 2009). Hence, instead of inventing a new type of individualism for every new epoch (see above), the challenge is to investigate on which of the two meaning dimensions value shifts occurs, which groups are involved in this and what are the possible counter-reactions in terms of value patterns. In this way, using the schema, we could get a less epochalist yet relational and gradual understanding of cultural shifts in individualism and avoid getting trapped in "the paradox of ever-renewing novelty" (Savage, 2009, p. 219).

\section{REFERENCES}

Alexander, J. (1982). Theoretical Logic in Sociology. Vol 1, Positivism, Presuppositions, and Current Controversies. Berkeley: University of California Press.

Beck, U. and Beck-Gernsheim, E. (2002). Individualization: Institutionalized Individualism and Its Social and Political Consequences. London: Sage.

Bell, D. (1976). The Cultural Contradictions of Capitalism. New York: Basic Books.

Bella, R., Madsen, R., Sullivan, W.M., Swidler, A., and Tipton S.M. (1985). Habits of the Heart: Individualism and Commitment in American Life. Berkley: University of California Press.

Berlin, I. (1969). Two Concepts of Liberty, in I. Berlin (ed.), Four Essays on Liberity (pp.118-72). Oxford: Oxford University Press.

Burckhardt, J. (1914). The Civilization of the Renaissance in Italy. London: Macmillan.

Boltanski, L. and Chiapello E. (2005). The New Spirit of Capitalism. London: Verso.

Bröckling, U. (2015). The Entrepreneurial Self: Fabricating a New Type of Subject. London: SAGE.Christman, John. 1991. "Liberalism and Individual Positive Freedom." Ethics 101 (2), 343-59.

Daenekindt, S. (2017). The Experience of Social Mobility: Social Isolation, Utilitarian Individualism, and Social Disorientation. Social Indicators Research, 133 (1), 15-30. https://doi.org/10.1007/s11205-016-1369-3

De Keere, K. (2014). From a self-made to an already-made man: A historic content analysis of professional advice literature. Acta Sociologica, 57(4), 311-324. https:// doi.org/10.1177/0001699314552737

De Keere, K. (2018). Political distinction: searching for a structural similarity between class and politics in Flanders (Belgium). European Societies, 20(3), 375-400. https:/ / doi.org/10.1080/14616696.2017.1371320

Dewey, J. (1999). Individualism Old and New. Amherst: Prometheus Books.

Dumont, L. (1977). Homo Aequalis: Genèse Épanouissement de L'idéologie Économique. Paris: Gallimard.

Durkheim, E. (1934). L'éducation Morale. Paris: Librairie Félix Alcan.

Durkheim, E. (1973). Individualism and the Intellectuals, in E. Durkheim, On Morality and Society (pp. 330-49). Chicago: University Of Chicago Press.

Elchardus, M. (2009). Self-Control as Social Control: The Emergence of Symbolic Society. Poetics, 37 (2), 146-61. https://doi.org/10.1016/j.poetic.2009.01.001

Elchardus, M. and De Keere, K. (2010). Institutionalizing the new self: a comparative analysis. European Societies, 12(5), 743-764. https://doi.org/10.1080/14616696.2010.514351

Elchardus, M. and De Keere, K. (2013). Social control and institutional trust: Reconsidering the effect of modernity on social malaise. The social science journal, 50(1), 101-111. https://doi.org/10.1016/j.soscij.2012.10.004

Elias, N. (1991). Society of Individuals. Oxford: Basil Blackwell Publisher.

Ferrara, A. (1998). Reflective Authenticity: Rethinking the Project of Modernity. London: Routledge.

Fichte, J-G. (1922). Adresses to the German Nation. Chicago: The Open Court Publishing Company.

Foucault, M. (1990). The History of Sexuality, Vol. 3: The Care of the Self. London: Penguin Books.

Foucault, M. (2008). The Birth of Biopolitics: Lectures at the College de France, 1978-1979. London: Palgrave Macmillan.

Freeden, M. (1996). Ideologies and Political Theory: A Conceptual Approach. Oxford; New York: Oxford University Press. 
Giddens, A. (1990). The Consequences of Modernity. Cambridge: Polity.

Hayek, F. (1948). Individualism and Economic Order. Chicago: University of Chicago Press.

Hochschild, A. (2016). Strangers in Their Own Land: Anger and Mourning on the American Right. New York: The New Press.

Holmes, S. (1997). Passions and Constraint: On the Theory of Liberal Democracy. University of Chicago Press.

Honneth, A. (2004). Organized Self-Realization Some Paradoxes of Individualization. European Journal of Social Theory, 7(4), 463-78. https://doi.org/10.1177/1368431004046703

Houtman, D., Achterberg, P. and Derks, A. (2008). Farewell to the Leftist Working Class. New Brunswick: Transaction Publishers.

Howe, D. (1997). Making the American Self: Jonathan Edwards to Abrabam Lincoln. Cambridge: Harvard University Press.

Illouz, E. (2008). Saving the Modern Soul: Therapy, Emotions, and the Culture of Self-Help. Berkeley: University of California Press.

Inglehart, R., and Welzel, C. (2005). Modernization, Cultural Change, and Democracy: The Human Development Sequence. Cambridge: Cambridge University Press. https:// doi.org/10.1017/CBO9780511790881

Kelemen, M., Mangan, A. and Moffat, S. (2017). More Than a 'Little Act of Kindness'? Towards a Typology of Volunteering as Unpaid Work. Sociology, 51(6), 1239-56. https:// doi.org/10.1177/0038038517692512

Kusserow, A. (2012). When Hard and Soft Clash: Class-Based Individualism in Manhattan and Queens. In S. Fiske and R. Markus, Facing Social Class: How Societal Rank. Influences Interaction (pp. 195-215). New York: Russell Sage Foundation.

Lamont, M. (1992). Money, Morals, and Manners: The Culture of the French and the American Upper-Middle Class. Chicago: University of Chicago Press. https://doi.org/10.7208/chicago/9780226922591.001.0001

Lamont, M. (2000). The Dignity of Working Men: Morality and the Boundaries of Race, Class, and Immigration. Cambridge, Mass.: Harvard University Press.

Lasch, C. (1991). The Culture of Narcissism: American Life in an Age of Diminishing Expectations. New York: W. W. Norton \& Company.

Lewin, P. and Williams, P. (2009). The Ideology and Practice of Authenticty in Punk Subculture, in P. Vannini (ed), Authenticity in Culture, Self, and Society (pp. 65-86). Surrey: Ashgate.

Lukes, S. (1973). Individualism. Guildford: Basil Blackwell Publisher.

McRobbie, A. (2015). Notes on the Perfect. Australian Feminist Studies, 30(83), 3-20. https://doi.org/10.1080/08164649.2015.1011485

Mills, C. W. (1960). Letter to the New Left. New Left Review, 5, 18-23.

Nussbaum, M. (1988). Non-Relative Virtues: An Aristotelian Approach. Midwest Studies in Philosophy, 13(1), 32-53. https://doi.org/10.1111/j.1475-4975.1988.tb00111.x

Pettit, P. (2001). A Theory of Freedom: From the Psychology to the Politics of Agency. Oxford: Oxford University Press.

Putnam, R. (2001). Bowling Alone: The Collapse and Revival of American Community. New York, Simon and Schuster.

Roger, C. (1961). On Becoming a Person: A Therapist View of Psychotherapy. Boston: Houghton Mifflin.

Rose, N. (1989). Governing the Soul: The Shaping of the Private Self. London: Free Association Books.

Rose, N. (1999). Powers of Freedom: Reframing Political Thought. Cambridge: Cambridge University Press. https:/ / doi.org/10.1017/CBO9780511488856

Savage, M. (2009). Against epochalism: An analysis of conceptions of change in British sociology. Cultural Sociology, 3(2), 217-238. https://doi.org/10.1177/1749975509105532

Sayer, A. (2011). Why Things Matter to People: Social Science, Values and Etbical Life. Cambridge: Cambridge University Press. https://doi.org/10.1017/CBO9780511734779

Seidman, S, and Meeks, C. (2011). The Politics of Authenticity: Civic Individualism and the Cultural Roots of Gay Normalization. Cultural Sociology, 5(4), 519-36. https://doi.org/10.1177/1749975511401272

Sennett, R. (2003). The Fall of Public Man. London: Penguin UK.

Simmel, G. (1950). The Sociology of Georg Simmel. Glencoe: The Free Press.

Skeggs, B. (2004). Class, Self, Culture. London: Routledge.

Spencer, H. (1851). Social Statistics. London: John Chapman.

Stephens, N., Markus, H. and Phillips, L. (2014). Social Class Culture Cycles: How Three Gateway Contexts Shape Selves and Fuel Inequality. Annual Review of Psychology, 65, 611-34. https://doi.org/10.1146/annurev-psych010213-115143

Stirner, M. (1907). The Ego and Its Own. New York: Benjamin Tucker Publisher.

Taylor, C. (1989). Sources of the Self: The Making of the Modern Identity. Cambridge: Harvard University Press.

Triandis, H. (1995). Individualism \& Collectivism: New Directions in Social Psychology. Boulder: Westview Press.

Wacquant, L. (2009). Punishing the Poor: The Neoliberal Government of Social Insecurity. Durham: Duke University Press Books. https:// doi.org/10.1215/9780822392255 
Welzel, C. (2010). How Selfish Are Self-Expression Values? A Civicness Test. Journal of Cross-Cultural Psychology, 41(2), 152-74. https://doi.org/10.1177/0022022109354378

Wilkinson, J. (2010). Personal Communities: Responsible Individualism or Another Fall for Public [Man]? Sociology, 44(3), 453-70. https://doi.org/10.1177/0038038510362484

Willis, P. (1977). Learning to Labor: How Working Class Kids Get Working Class Jobs. New York: Columbia University Press.

Wuthnow, R. (1995). Learning to Care: Elementary Kindness in an Age of Indifference. Oxford: Oxford University Press. 